\title{
ENGEVISTA
}

Página da revista: http://www.uff.br/engevista/seer/

\section{Modelagem e avaliação do processo de degomagem no refino de óleo de soja}

\author{
Gerusa Oliveira Rosa ${ }^{1}$ \\ Fernando Castro Vieira Filho ${ }^{2}$ \\ Luiz Mario Matos Jorge ${ }^{3}$ \\ Paulo Roberto Paraíso 4 \\ Cid Marcos Gonçalves Andrade ${ }^{5}$
}

Resumo: A produção de óleo de soja é um importante setor do agronegócio mundial. O Brasil é um dos grandes produtores mundiais deste produto, mas enfrenta grande concorrência no mercado internacional de outros países produtores. Para ser competitivo neste mercado, faz-se necessário atuar intensivamente no processo de refino para produzir óleo com qualidade e baixo custo operacional. No processo de refino, a etapa de degomagem garante a separação das gomas presentes no óleo de soja. Este trabalho tem como principal objetivo modelar e avaliar a operação industrial de degomagem a fim de possibilitar a redução de perdas operacionais e a geração de óleo de melhor qualidade. Para tanto, foi realizado um estudo do processo para verificar a influência das variáveis e parâmetros envolvidos na degomagem. Em seguida, foi desenvolvido o modelo matemático do processo que foi validado com dados operacionais da indústria. Além disso, diversas simulações desta operação foram realizadas a fim de avaliar as melhores condições do processo. Os resultados obtidos foram satisfatórios, o modelo desenvolvido representou bem o processo de degomagem, a variável de dosagem de água não exerceu influência sobre a perda de óleo arrastada e em contrapartida, o parâmetro operacional de ajuste da pressão influenciou diretamente..

Palavras-chave: Degomagem, óleo de soja, modelagem matemática.

\footnotetext{
${ }^{1}$ UEM - Universidade Estadual de Maringá

${ }^{2}$ UEM - Universidade Estadual de Maringá

${ }^{3}$ UEM - Universidade Estadual de Maringá

${ }^{4}$ UEM - Universidade Estadual de Maringá

${ }^{5}$ UEM - Universidade Estadual de Maringá
} 
ISSN: $1415-7314$

ISSN online: $2317-6717$

\begin{abstract}
The soybean oil production is an important sector of world agribusiness. Brazil is one of the great world producers of this product, but it faces hard competition in international markets from other producing countries. To be competitive in this market, it's necessary to operates extensively in the refining process to produce quality oil and low operating cost. In the refining process, the degumming step ensures separation of the gums present in the soybean oil. This work aims to mould and to analyze the degumming industrial operationin, order to decrease operational losses and to produce better quality oil. Thus, a study of the process was realized to verify the influence of the variables and parameters involved in the degumming. After that, the mathematical model of the process which was validated with the industry operational data was developed. Moreover, several simulations of this operation were realized to verify the best process conditions. The results obtained were satisfactory and the developed model represented well the degumming process. The variable amount of water didn't exert influence on the loss of dragged oil and in compensation, the operating parameter of pressure adjustment influenced directly.
\end{abstract}

Keywords: Degumming, soybean oil, mathematic modeling. 


\section{Introdução}

O Brasil é o segundo maior produtor mundial de soja, estando atrás apenas dos Estados Unidos. Segundo MAPA (2014) o departamento de Agricultura dos Estados Unidos projetou para o exercício 2014/2015 uma safra americana, próxima dos 104,0 milhões de toneladas.

O complexo soja é o destaque das exportações brasileiras do agronegócio e, no período de agosto/2013 a julho 2014, o valor exportado atingiu US\$ 33 bilhões, representando um aumento de 19,6\% em relação ao mesmo período do ano anterior (MAPA, 2014).

Segundo Paraíso et al (2002) a industrialização de oleaginosas constitui-se num dos mais importantes setores do sistema agroindustrial, pela importância de seus produtos nas indústrias siderúrgicas, de cosméticos e como matéria prima no processamento de alimentos para o consumo humano. Os produtos gerados atendem o mercado interno e externo, e para serem competitivos, necessitam sempre buscar a redução de custos operacionais. Dentro deste contexto inclui a industrialização da soja, que através do processo de extração obtém como principais produtos farelo e óleo de soja.

Destaca-se que a operação industrial de obtenção do óleo de soja em grande escala normalmente utiliza solvente orgânico para a extração do óleo presente na semente. O solvente é separado do óleo. Desta forma, como este óleo ainda contém substâncias inadequadas para o consumo humano o mesmo passa por várias operações de refino. Segundo Erickson (2000) o refino de óleo de soja possui a finalidade de eliminar as impurezas solúveis no óleo a fim de adquirir melhores padrões de qualidade no sabor, aparência e estabilidade, merecendo como consequência a aceitação do consumidor.

Dentre as operações de refino existe a degomagem, que segundo Dijkstra (2000), possui a função de produzir um óleo livre de gomas, as quais implicam resíduos indesejáveis, principalmente no transporte e armazenamento do óleo.

As gomas produzidas no processo de degomagem, conhecida comercialmente como lecitina, possui valor comercial, principalmente na indústria de alimentos, sendo utilizada como emulsificante.

No que tange à operacionalização efetiva da degotarem, vê-se que esta exige adição expressiva de água ao óleo que forma uma emulsão. Este material passa por um processo de separação em centrífugas que gera duas correntes. Uma corrente é denominada de óleo degomado e a outra corrente é formada pelas gomas também designada industrialmente de lecitina. Ao concretizar esta operação de separação, ocorre um consumo elevado de água e energia. Além disso, prevalece a preocupação constante com a qualidade do óleo degomado. Portanto, é fundamental que a degomagem opere nas melhores condições com o intuito de reduzir o consumo de água, de energia e aperfeiçoar os parâmetros de qualidade do óleo. 
Vários pesquisadores desenvolveram estudos relacionados à indústria de óleo de soja para estabelecer as melhores condições operacionais dos processos a fim de reduzir custos e melhorar a qualidade do produto. Kemper (1998) publicou um trabalho que quantificava as perdas de solvente na indústria de óleo de soja; ainda Kemper (2000), apresenta um trabalho com inovações para a redução do consumo de energia no dessolventizador-tostador; Paraíso et al (2002) desenvolveu um trabalho de análise energética do processo de obtenção do óleo de soja; ainda Paraíso et al $(2003,2005,2008)$ realizou respectivamente a modelagem e simulação para a evaporação do hexano no processo de extração do óleo, modelagem e simulação do Stripping do Hexano, e modelagem e simulação no desolventizador -tostador do processo de óleo de soja.

Desta forma, o presente trabalho tem como objetivo realizar a modelagem do processo de degomagem visando à identificação e quantificação das perdas, contribuindo para a complementação do estudo da cadeia de industrialização do óleo de soja.

Nesta modelagem pretende avaliar os parâmetros que afetam as perdas indesejáveis do arraste e óleo decorrente do processo de centrifugação e a qualidade do produto final e desenvolver um modelo matemático para a separação das gomas. Este modelo foi validado com dados industriais.

\section{Materiais e métodos}

\subsection{Equipamentos utilizados na degomagem}

O processo de degomagem é realizado para fornecer um óleo que esteja apto para longo tempo de estocagem, produzir lecitinas e preparar um óleo com baixos teores de gomas para que o processo de neutralização tenha eficiência na separação dos sabões e baixo consumo de agentes neutralizadores.

As especificações de comercialização do óleo de soja são fixas para um limite superior de 200 ppm para o fósforo residuais especificados pela NOPA(National Oilseed Procesor Association).

Os principais métodos de degomagem utilizadas pelas indústrias são: com água, ácida, superdegomagem, enzimática e por menbranas. Os dois primeiros métodos são os mais usados devido seu baixo custo de operação e por obter resultados satisfatório no processo ( Ribeiro et al, 2008)

A quantidade de água, a temperatura e a eficiência da centrifugação são os fatores que influenciam na oclusão do óleo. Santos e Zanetti (1981) mostra 0,5 a 3\% de água normalmente a proporção mais adequada através de ensaios em laboratórios. Normalmente a temperatura de separação situa-se entre 55 e $82^{\circ}$, sendo mais adequada a centrifugação a $75^{\circ} \mathrm{C}$.

$\mathrm{Na}$ degomagem com água a etapa mais importante quando se refere a rendimentos é a centrifugação em centrífugas, que geralmente ocorre em centrífugas de discos. Nesta etapa os 
fosfatideos hidratáveis reagem com a água formando a goma (lecitina) e é nesta operação que ocorre a eliminação das mesmas. Para Harten e Eickhoff (2000) as centrífugas de disco devem ser utilizadas para separar líquidos de densidades diferentes, nos quais são solúveis entre si. A mistura de líquido ingressa num tambor rotativo e através de um tubo de alimentação estacionário. A distribuição do mesmo é acelerada a velocidade angular o recipiente e enviada para a coluna de discos.

A separadora utilizada neste trabalho é uma centrífuga Alfa Laval SSG214H-1 de discos autolimpante. A corrente de entrada na centrifuga é o óleo aquecido em um trocador de placas juntamente com água de hidratação, ou seja, o óleo hidratado, as correntes de saída são caracterizadas pela eliminação das gomas e a saída do óleo degomado úmido que posteriormente passa pelo processo de secagem a vácuo. Os parâmetros de operacionais, como temperatura, vazões são monitorados e ajustados via supervisório. $\mathrm{O}$ processo industrial em análise é interligado a uma planta de extração de óleos vegetais por meio do qual envia o óleo para degomagem a uma temperatura média de $98^{\circ} \mathrm{C}$. O óleo passa por um tanque onde é adicionado água para hidratação. Após a hidratação, o óleo passa pela centrífuga de disco ode ocorre a separação das gomas, logo o óleo segue para um tanque flash para secagem antes da transferência para o processo de neutralização

A Figura 1 representa um processo simples de degomagem com adição de água.

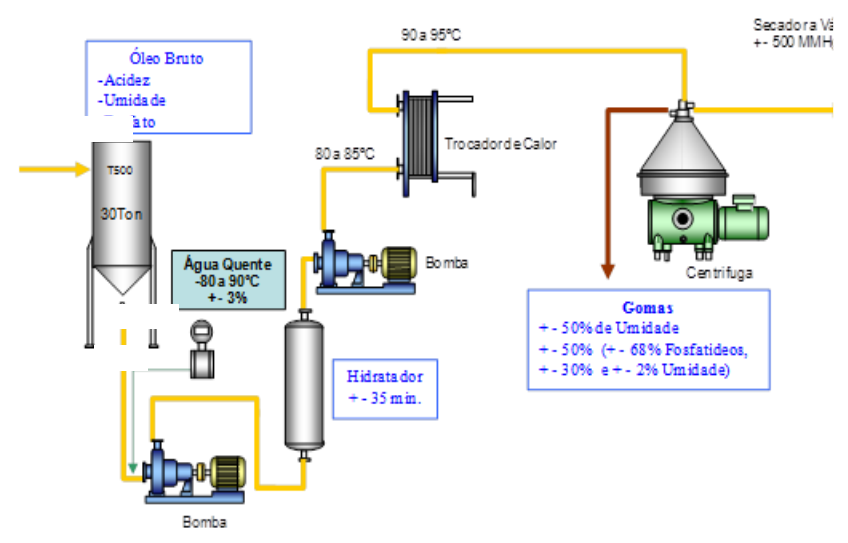

Figura 1. Instalação de degomagem com água.

Nesta figura óleo bruto armazenado em um tanque é bombeado simultaneamente com adição de água aquecida para um tanque de hidratação, em seguida o óleo hidratado passa por um trocador de calor para aquecimento e na sequência inicia-se o processo de centrifugação com a separação das gomas e do óleo degomado. 


\subsection{Procedimento experimental e levantamento de dados}

Os dados coletados nas correntes de óleo degomado e óleo bruto foram vazão, umidade, teor de fósforo, impureza insolúveis. Na corrente de lecitina os dados coletados foram vazão, umidade e teor de óleo arrastado. Os procedimentos utilizados nesta coleta estão descritos abaixo:

\subsubsection{Procedimento para obtenção de dados de vazão}

O objetivo deste procedimento é verificar como as vazões de óleo e água influencia nos parâmetros de qualidade do processo.

A temperatura manteve-se em $90^{\circ} \mathrm{C}$, temperatura padrão da operação deste processo na indústria em análise.

A vazão de entrada de água para operar com dosagens de água com uma variação 4,5\% a $7 \%$ na corrente de alimentação. Para cada experimento e aguardou-se 40 minutos para obter as condições de regime permanente. A vazão de óleo bruto operou com vazões na faixa de 11000 a $14000 \mathrm{Kg} / \mathrm{h}$. Para cada experimento foram coletas 3 amostras de pontos específico do processo: óleo bruto no tanque de alimentação, a lecitina e óleo degomado dos bocais de saída da centrifuga.

Utilizou uma parte do conjunto de amostra (óleo bruto+ lecitina+ óleo degomado) para realizar a análise de umidade em base úmida $(X b u)$, de acordo com a Equação 1, medindo o peso da amostras antes $(M U)$ e depois da secagem $(M S)$ pelo método clássico de secagem a peso constante.

$$
X b u=\frac{M U-M S}{M U}
$$

A análise de fósforo baseou-se no método oficial AOCS (American Oil Chemists Society) (1998) Ca 12-55 que determina o equivalente em fosfatídeo contido na amostra calcinada na presença de óxido de zinco, seguido da medida espectrofotométrica de fósforo como um complexo azul ácido fosfomolíbdico. O cálculo do percentual de fósforo em cada amostra de óleo bruto e óleo degomado foi obtido pela equação 2, pesando a massa de fósforo contido na amostra $(F s)$, a massa de fósforo contido no branco $(F a)$, peso da amostra $(M)$ e o volume da alíquota $(\mathrm{Va})$, temos:

$$
\text { Fósforo } \%=\frac{10(F a-F s)}{M * V a} * 10.000
$$

Para determinar a impureza nas amostras de óleo bruto e óleo degomado, seguiu-se o método oficial AOCS (American Oil Chemists Society) (1998) Ca 3a-46 que analisa substancias estranhas insolúveis em querosene e éter de petróleo. O cálculo da impureza é realizado pela 
equação 3, pesando a massa do preparado seco $(M s)$, a massa com o resíduo seco $(M r s)$ e a massa da amostra $(M A)$, temos:

$$
\text { Im purezas } \%=\frac{M r s-M s}{M A * 100}
$$

Os sabões foram determinados pela equação 4, utilizando o método oficial da AOCS ( American Oil Chemists Society) (1998) Cc 17-95. Por meio da titulação com a solução de ácido clorídrico $(0,005 \mathrm{M})(G)$ e o peso da amostra $(M A)$, temos:

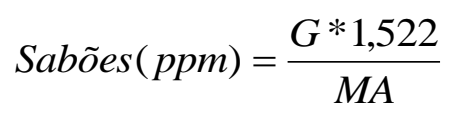

Parte da amostra de lecitina foi utilizada para determinar o conteúdo total de óleo presente na amostra pelo método de extração com acetona e os cálculo de óleo presente na amostra foram realizados pelas equações 5 e 6 , onde $(P B O)$ representa o peso balão volumétrico com óleo, $(P B V)$ o peso do balão volumétrico vazio, $(P A)$ o peso da amostra, $(A B U)$ teor de óleo arrastado na base úmida e $(A B S)$ teor de óleo arrastado na base seca.

$$
\begin{gathered}
A B U(\%)=\frac{(P B O)-(P B V)}{P A} * 100 \\
A B S(\%)=\frac{(P B O)-(P B V)}{[P A-(P A-\% \text { umidade }) / 100} * 100(6)
\end{gathered}
$$

A partir dos resultados das análises foram realizados os cálculos de pureza do óleo na corrente de alimentação e na saída do óleo degomado e realizado o balanço material do óleo de cada experimento.

\subsubsection{Procedimento de variação na pressão de operação da centrifugação}

O objetivo deste procedimento é verificar a influência da variação da pressão de operação da centrífuga nos parâmetros de qualidade do processo.

A pressão da centrifuga varia na faixa de 0,9 a 1,9 Kgf/bar, aguardou-se 30 minutos para obter condições de regime permanente e foi realizada a coleta de dados nas correntes de entrada e saída.

\subsection{Modelagem matemática}

Modelagem desenvolvida neste trabalho baseia-se em equações de conservação de massa e quantidade de movimento. Foust et al (2000) propuseram um modelo baseado em balanços de forças que possibilita prever diversas propriedades envolvidas no processo de centrifugação. Bird 
et al (2005) indicaram um modelo respaldado no balanço de massa binário macroscópico, que permite estimar as composições das correntes de saída envolvidas no processo.

\subsubsection{Balanço de Força na Centrifugação}

De acordo com Foust et al (2000), no escoamento de um fluido em regime permanente, sobre um corpo sólido, formam-se camadas limites e o fluido exerce uma força sobre o sólido. Esta força está expressa em termo de um coeficiente de arraste $C_{A}$ equação 7:

$$
C_{A}=\frac{2 F_{A}}{V_{c l}^{2} \rho S}
$$

Onde $F_{A}$ é a força que atua sobre o sólido, $V_{c l}$ é velocidade da corrente livre em relação à partícula, e $S$ área de seção reta na direção normal ao escoamento.

Uma partícula em movimento linear move-se através de um fluido, sob ação de uma força externa. A teoria do movimento dos sólidos através dos fluidos tem a sua base no conceito do movimento dos corpos livres, expressa na Equação 8:

$$
F g_{c}=m \frac{d v}{d t}
$$

Sendo $F g_{c}$ a força resultante que atua sobre qualquer corpo, $d v / d t$ a aceleração do corpo, e $m$ a massa do corpo. O Balanço de força é dado por:

$$
\left(F_{E}-F_{A}-F_{B}\right) g_{c}=m \frac{d v}{d t}
$$

Onde $\left(F_{E}\right)$ é a força externa, $\left(F_{B}\right)$ a força do empuxo e a força de arraste $\left(F_{A}\right)$.

Combinando as Equações 7 a 9 obtém-se:

$$
\frac{d v}{d t}=a_{E}-\frac{\rho a_{E}}{\rho_{s}}-\frac{C_{A} V_{c l}^{2} \rho S}{2 m}
$$

$\mathrm{Na}$ equação 10 temos a força de arraste, $a_{E}$ é aceleração da partícula resultante da fora externa. Se a força externa é proveniente de um campo centrífugo, onde $a_{E}=r \omega^{2}$, onde $r$ o raio no ponto da trajetória e $\omega$ é a velocidade angular, em radianos por segundo, temos a equação 11 que representa o balanço de forças em torno de uma partícula que cai em um campo centrífugo.

$$
\frac{d v}{d t}=r \omega^{2}\left(1-\frac{\rho}{\rho_{s}}\right)-\frac{C_{A} \rho V_{c l}^{2} \rho S}{2 m}
$$


Considerando o regime laminar então $C_{A}=24 / N_{\mathrm{Re}}$. Considerando a equação para partículas esférica, temos:

$$
\frac{d v}{d t}=r \omega^{2}\left(\frac{\rho_{s}-\rho}{\rho_{s}}\right)-\frac{18 \mu v}{\rho_{s} D_{p}^{2}}
$$

Considerando-se a velocidade em qualquer posição, $d v / d t=o$; porém em qualquer instante do movimento de uma única partícula, $d v / d r$ é positiva a equação 12 reduzem a Equação 13:

$$
V_{R}=\frac{r \omega^{2}\left(\rho_{2}-\rho\right) D_{p}^{2}}{18 \mu}
$$

Onde $V_{R}$ é a velocidade terminal de partículas esféricas de diâmetro $D_{p}$ no ponto de raio $r$ num campo centrífugo cuja velocidade angular de rotação é $\omega$.

A distância radial percorrida pela partícula pode ser obtida multiplicando-se a Equação 13 pelo elemento infinitesimal de tempo $d t$ e integrando tem:

$$
\ln \frac{r_{2}}{r_{1}}=\frac{\omega^{2}\left(\rho_{s}-\rho\right) D_{p}^{2}}{18 \mu} \theta=\frac{\omega^{2}\left(\rho_{s}-\rho\right) D_{p}^{2}}{18 \mu} * \frac{V}{Q}(14)
$$

Onde $V$ é o volume do material presente na centrífuga, $Q$ a taxa volumétrica de alimentação da centrífuga e $V / Q$ o tempo de residência de uma partícula no centrifugador. $\mathrm{O}$ diâmetro que aparece na Equação 14 é o de uma partícula que cai entre ${ }^{r_{1}}$ e $r_{2}$ durante o tempo de residência que lhe é próprio.

$$
V_{R} t=\frac{r \omega^{2}\left(\rho_{s}-\rho\right) D_{p}^{2}}{18 \mu} * \frac{V}{Q}
$$

Resolvendo a equação 15 em $Q$, inserindo-se ao mesmo tempo a aceleração da gravidade temos a equação 16 :

$$
Q=\frac{\left(\rho_{s}-\rho\right) g D_{p}^{2}}{9 \mu} * \frac{V \omega^{2} r}{g\left(r_{2}-r_{1}\right)}=2 v_{t} * \Sigma
$$

Onde $v_{t}$ é a velocidade de sedimentação é apresentado e $\Sigma$ é o poder de separação.

A velocidade de sedimentação está relacionada com as características do produto a ser centrifugado e o poder de separação está relacionado com a engenharia do equipamento. 
Somente a aceleração efetiva é influenciada pela construção do equipamento, logo a separação no seio do líquido dependerá da rotação escolhida, ou seja, de um fator de separação que será dado pela relação entre a aceleração centrífuga e gravitacional, dado pela equação abaixo.

$$
\alpha=\frac{r^{*} \omega^{2}}{g}
$$

No caso do centrifugador a discos, a fórmula do poder de separação é dada pela equação 18.

$$
\sum=\frac{2 n \pi\left(r_{2}^{3}-r_{1}^{3}\right) \omega^{2}}{3 g \tan \Omega}
$$

Perry's e Chilton (1984) menciona que uma centrifuga de disco com diâmetro de 13 a 24 polegadas tem um fator de separação de 5.500 a 10.400 .

\subsubsection{Balanço de Massa na Centrifuga}

Considerando o processo de centrifugação como um processo binário, admitindo que a corrente de entrada composta de óleo e gomas e as duas correntes de saída goma e óleo separado utilizamos o modelo dinâmico considerando um sistema binário exposto, Bird et al (2005), onde o autor coloca o modelo como uma forma de calcular processo de separação macroscópico em base molar, o mesmo é obtido por meio de equações de balanço de massa, considerando-se a presença da fase sólida e uma fase líquida apresentado na Figura 2.

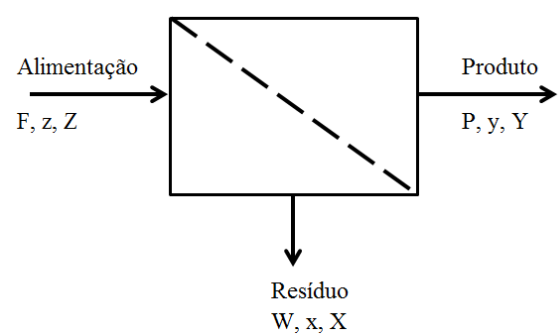

Figura 2. Processo de Separação Binária na Centrifuga

Os cálculos realizados utilizados modelo foram feitos com base mássica, a fim de minimizar os erros no processo de conversão. A fim de simplificar foram utilizadas hipóteses de que o tempo de residência, densidade, temperatura, calores específicos são mantidos constantes. A perda de carga no processo é desprezível e o processo não possui reações químicas apenas transformações físicas.

O balanço de massa no separador binário é dado pelas equações do balanço de massa global e componente de óleo de soja: 


$$
\begin{aligned}
& F=W+P \\
& F_{z}=W_{x}+P_{y}
\end{aligned}
$$

Considerando a mistura binária composta de óleo e goma que entra na centrifuga em uma corrente de alimentação a uma taxa mássica $F$. Em seguida pelo mecanismo de separação centrifuga é dividida em um fluxo de produtos mássico $P$ e um fluxo mássico de resíduo (goma) $W$. A fração mássica do óleo de soja (o componente desejado) no fluxo de alimentação é $z$, e as frações mássicas do produto e do resíduo são ${ }^{y} \mathrm{e}^{x}$ respectivamente.

Define-se uma razão de corte $\theta=P / F$ taxas do fluxo do produto, onde temos (óleo degomado) e de alimentação (óleo bruto). Substituindo a razão de corte na equação 19 e eliminando $W$ na equação 20 , temos:

$$
z=\theta y+(1-\theta) x
$$

Agora, escrevendo a relação entre a alimentação e composição de resíduos, a equação que relaciona as composições das duas correntes de saída, são:

$$
Y=\alpha X
$$

Onde $\alpha$ é o fator de separação

Em termos de frações mássicas temos as seguintes equações:

$$
\begin{aligned}
& y=\frac{\alpha x}{1+(\alpha-1) x} \\
& x=\frac{y}{\alpha-(\alpha-1) y}
\end{aligned}
$$

As equações 23 e 24 descrevem completamente a operação de separação do óleo de soja com a lecitina. Para esta situação definiu-se um separador ideal em termos de uma operação na qual o produto e fluxos de resíduos estão em equilíbrio.

O modelo proposto para um balanço de massa macroscópico pode ser utilizado para diferentes processos de separações, por exemplo, difusões térmicas, centrifugações, entre outros. A equação 25 define o fator de separação para um modelo centrifugo.

$$
\alpha=1+\frac{y-x}{x(1-y)}
$$

Nas centrífugas de acordo Harten (2000) os parâmetros relacionados com o produto para a determinação da capacidade de rendimento de uma centrífuga, segue a lei de Stokes. Segundo 
Dorsa (2004) velocidade de decantação de sólidos na separação centrífuga aumenta com aumento na diferença de densidade entre partículas sólida e óleo, aumento do diâmetro da partícula sólida, diminuição da viscosidade do óleo e a aceleração efetiva devido à gravidade.

\section{Resultados e discussão}

\subsection{Análises laboratoriais das correntes}

As tabelas abaixo estão os resultados das análises da composição das três correntes do processo em estudo.

As amostras coletadas na corrente de entrada de óleo bruto estão listadas na Tabela 1. Este fornece dados sobre principais componentes do óleo de soja bruto em percentuais: fósforo (fosfatídeos hidratáveis e não hidratáveis) 0,079 a 0,101 sabões (sais de ácidos graxos) 0,152 a 0,205, impurezas 0,011 a 0258, água utilizada na hidratação 4,826 a 7,129, considerando que o óleo bruto a ser degomado apresentou uma concentração que o óleo bruto a ser degomado apresentou uma concentração de 92,552 a 94,845\%.

Tabela 1. Dados da corrente de entrada- Óleo Bruto e água

\begin{tabular}{cccccc}
\hline $\begin{array}{c}\text { Vazão de } \\
\text { Entrada kg/h }\end{array}$ & $\begin{array}{c}\text { \% água de } \\
\text { hidratação }\end{array}$ & \% sabões & \% fosforo & \% impurezas & \% oleo \\
\hline 13791 & 6,176 & 0,194 & 0,079 & 0,015 & 93,536 \\
12500 & 5,623 & 0,189 & 0,083 & 0,028 & 94,078 \\
13780 & 6,191 & 0,205 & 0,103 & 0,089 & 93,411 \\
12750 & 5,736 & 0,160 & 0,082 & 0,080 & 93,943 \\
12779 & 6,610 & 0,202 & 0,088 & 0,077 & 93,022 \\
13764 & 6,158 & 0,175 & 0,100 & 0,015 & 93,552 \\
13341 & 6,416 & 0,191 & 0,110 & 0,014 & 93,269 \\
11810 & 7,129 & 0,228 & 0,074 & 0,018 & 92,552 \\
13425 & 4,852 & 0,178 & 0,101 & 0,054 & 94,815 \\
12632 & 5,775 & 0,152 & 0,098 & 0,258 & 93,717 \\
12704 & 6,603 & 0,193 & 0,088 & 0,211 & 92,906 \\
13351 & 6,364 & 0,152 & 0,093 & 0,011 & 93,379 \\
14672 & 4,826 & 0,158 & 0,101 & 0,110 & 94,008 \\
14618 & 5,591 & 0,190 & 0,094 & 0,093 & 93,126 \\
14703 & 6,496 & 0,190 & 0,079 & 0,018 & 94,642 \\
14176 & 5,094 & 0,168 & 0,092 & 0,032 & 93,801 \\
14200 & 5,880 & 0,195 & 0,086 & 0,050 & 95,168 \\
\hline
\end{tabular}

As amostras coletadas na corrente de entrada de óleo Na Tabela 2 os dados da corrente de saída do óleo degomado mostra uma redução nos compostos indesejáveis do óleo bruto: fósforo a uma média de $0,023 \%$, sabões a $0,010 \%$, umidade a $0,519 \%$ e impurezas a $0,026 \%$. A concentração foi em média $99,432 \%$. 
De acordo com Santos e Zanetti (1981) a lecitina bruta apresenta um teor de óleo de 17\% e 50\% de água. Nos experimentos foi obtida uma média de 55\% para umidade, valor próximo do exposto pelos autores anteriores, no entanto, o arraste de óleo na lecitina está bem elevado com uma média de $41,7 \%$, logo se conclui que o processo possui oportunidades de melhoria. Os resultados estão na Tabela 3 .

Tabela 2. Dados da composição da corrente de saída Óleo degomado

\begin{tabular}{cccccc}
\hline $\begin{array}{c}\text { Vazão de Saída } \\
\mathrm{kg} / \mathrm{h}\end{array}$ & \% umidade & \% sabões & \% fosforo & \% impurezas & $\%$ oleo \\
\hline 12.413 & 0,487 & 0,007 & 0,027 & 0,022 & 99,457 \\
11.245 & 0,500 & 0,011 & 0,025 & 0,028 & 99,435 \\
12.310 & 0,528 & 0,011 & 0,024 & 0,022 & 99,414 \\
11.517 & 0,510 & 0,010 & 0,030 & 0,020 & 99,430 \\
11.380 & 0,505 & 0,009 & 0,025 & 0,024 & 99,437 \\
12.400 & 0,420 & 0,009 & 0,021 & 0,017 & 99,534 \\
12.029 & 0,516 & 0,009 & 0,023 & 0,021 & 99,430 \\
10.375 & 0,503 & 0,011 & 0,027 & 0,018 & 99,441 \\
12.481 & 0,468 & 0,010 & 0,020 & 0,019 & 99,484 \\
11.310 & 0,530 & 0,012 & 0,020 & 0,032 & 99,406 \\
11.361 & 0,488 & 0,014 & 0,020 & 0,097 & 99,381 \\
11.940 & 0,527 & 0,008 & 0,021 & 0,024 & 99,420 \\
13.379 & 0,538 & 0,011 & 0,022 & 0,000 & 99,429 \\
13.234 & 0,577 & 0,012 & 0,018 & 0,021 & 99,371 \\
13.107 & 0,478 & 0,009 & 0,021 & 0,002 & 99,490 \\
12.967 & 0,510 & 0,010 & 0,020 & 0,040 & 99,420 \\
12.854 & 0,527 & 0,010 & 0,021 & 0,030 & 99,411 \\
13.363 & 0,512 & 0,014 & 0,021 & 0,024 & 99,429 \\
\hline
\end{tabular}

Tabela 3. Dados da composição da corrente de saída Lecitina

\begin{tabular}{rrrrr}
\hline Vazão kg/h & \% umidade & $\begin{array}{c}\text { \% Óleo } \\
\text { arrastado }\end{array}$ & $\begin{array}{c}\text { Oleo arrastado } \\
\mathrm{Kg} / \mathrm{h}\end{array}$ & \% Perda de Óleo \\
\hline 1.378 & 57,700 & 40,196 & 553,907 & 4,294 \\
1.255 & 51,473 & 46,064 & 577,951 & 4,915 \\
1.470 & 53,610 & 43,141 & 634,168 & 4,927 \\
1.233 & 54,500 & 42,687 & 526,327 & 4,394 \\
1.399 & 56,277 & 40,832 & 571,149 & 4,805 \\
1.364 & 57,974 & 39,187 & 534,623 & 4,152 \\
1.312 & 60,476 & 36,776 & 482,481 & 3,878 \\
1.435 & 54,931 & 42,728 & 612,953 & 5,608 \\
944 & 62,801 & 33,087 & 312,348 & 2,454 \\
1.322 & 50,839 & 45,052 & 595,588 & 5,031 \\
1.343 & 58,303 & 38,134 & 512,188 & 4,340 \\
1.411 & 55,711 & 42,271 & 596,528 & 4,785 \\
1.293 & 53,617 & 47,771 & 617,872 & 4,480 \\
1.384 & 55,857 & 42,726 & 591,351 & 4,344 \\
1.596 & 54,235 & 40,881 & 652,650 & 4,690 \\
1.209 & 57,020 & 43,406 & 524,856 & 3,947 \\
1.346 & 50,822 & 40,209 & 541,090 & 4,004 \\
\hline
\end{tabular}




\subsection{Validação do modelo}

Para a validação do modelo foi utilizado o fator de separação calculada pela equação 18 , e, através das medidas realizadas do raio dos discos e da velocidade angular, obtendo assim um fator de separação de 9880 próximos aos valores citados anteriormente por Perry's e Chilton (1984). Os dados foram obtidos considerando uma temperatura constante. Os resultados dos dados simulados frente aos dados experimentais estão expostos nas Figuras 03 e 04.

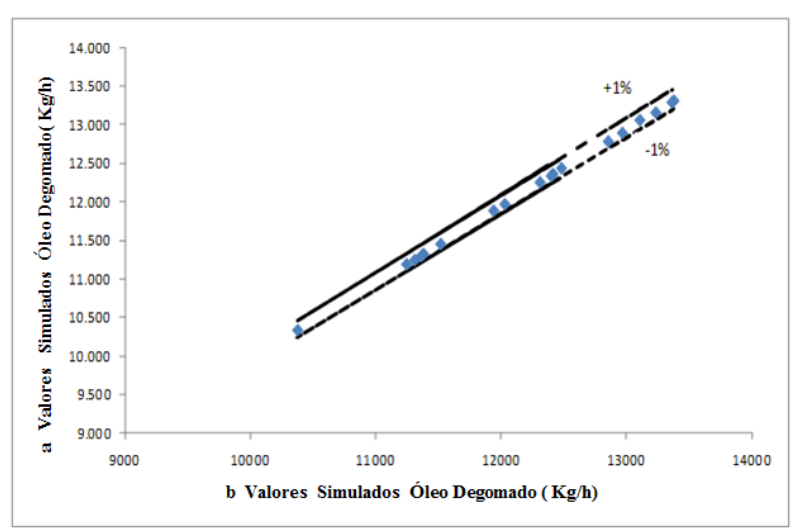

Figura 3. Valores Simulados a versus b valores experimentais para a corrente de óleo degomado.

Nesta comparação entre os dados simulados e os dados experimentais da Figura 4, o modelo obteve dados satisfatórios com erros inferiores a 5\% para a corrente de saída de do óleo.

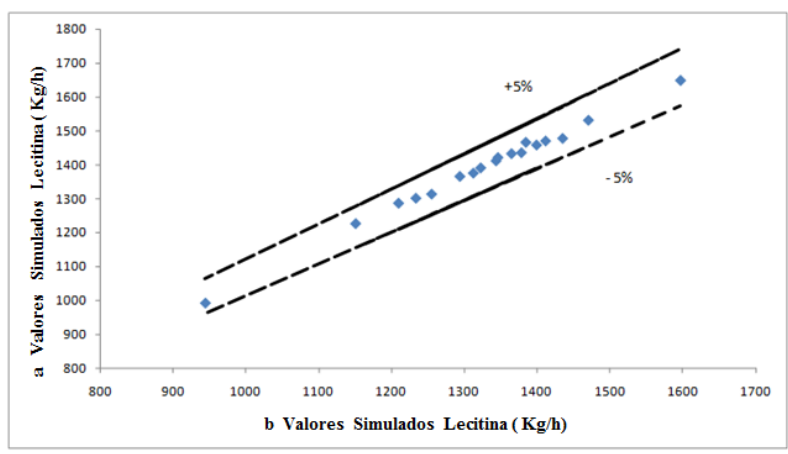

Figura 4. Valores simulados a versus b valores experimentais para corrente de saída.

A comparação entre os dados simulados e os experimentais para a composição das correntes entradas e saídas do processo estão na Tabela 4. 
Tabela 4. Dados experimentais frente aos dados simulados para as correntes de saída do processo de degomagem de óleo de soja.

\begin{tabular}{|c|c|c|c|}
\hline CORRENTES DE SAÍDA & RESULTADOS EXPERIMENTAIS & RESULTADOS SIMULADOS & $\%$ Erro \\
\hline $\begin{array}{l}\text { P-Vazão de Óleo Degomado } \\
(\mathrm{Kg} / \mathrm{h})\end{array}$ & 13106,52 & 13056,264 & $0,38 \%$ \\
\hline W - Vazão de Lecitina $(\mathrm{Kg} / \mathrm{h})$ & 1596,48 & 1646,7136 & $3,10 \%$ \\
\hline y- Fração mássica de óleo (\%) & 0,9949 & 0,9998 & $0,50 \%$ \\
\hline $\begin{array}{c}\text { x - Fração mássica de óleo na } \\
\text { Lecitina (\%) }\end{array}$ & 0,402 & 0,380 & $5,80 \%$ \\
\hline
\end{tabular}

Variando se a corrente de entrada do óleo bruto e o fator de separação proposto, no intervalo de operação do processo, foram obtidos o comportamento do modelo para fração de óleo na corrente de saída e comparados com os dados experimentais na Figura 5 .

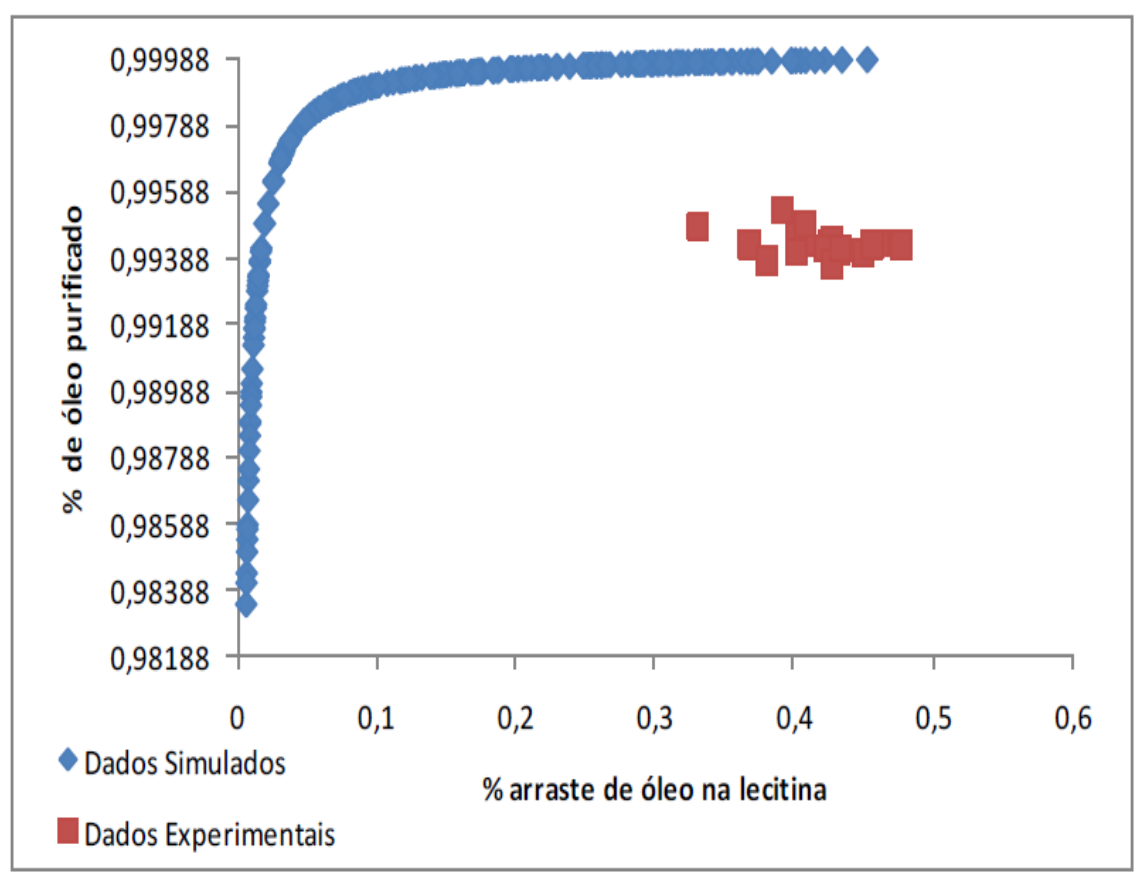

Figura 5. Dados simulados frente aos dados experimentais.

Nesta comparação, entre os dados simulados e os dados experimentais, o modelo adquiriu um comportamento satisfatório. 


\subsection{Avaliação da adição de água}

A seguir apresenta-se a Figura 6 onde mantivemos constante a vazão do óleo e variou a vazão da água.

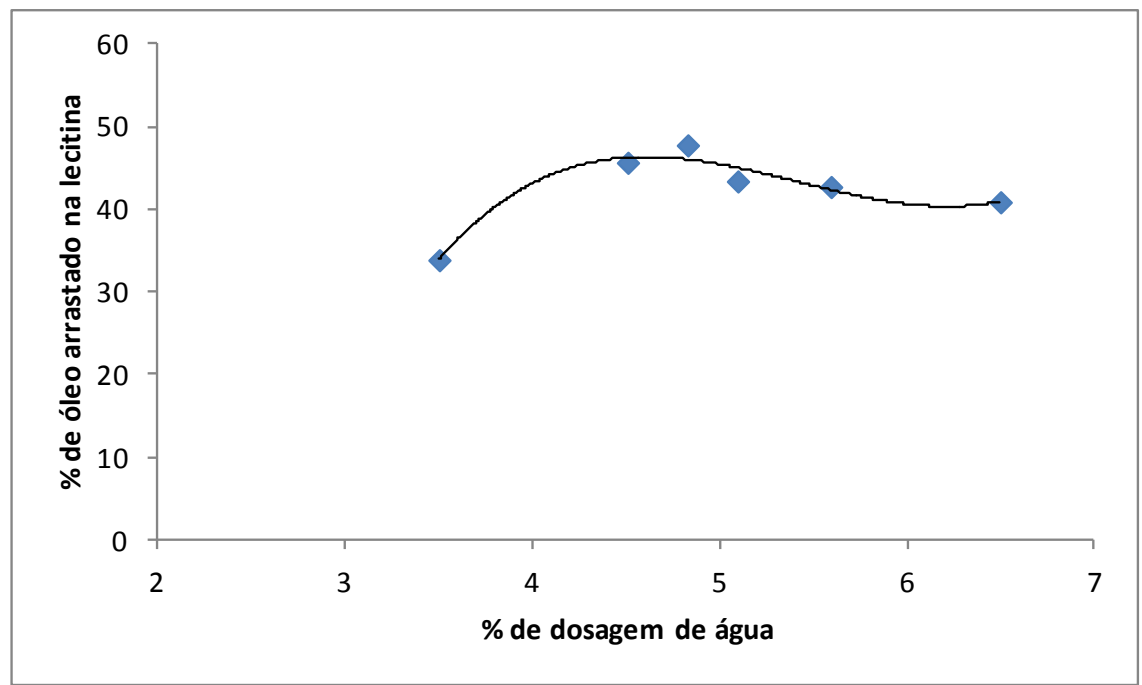

Figura 6. Variação da dosagem de água em relação ao óleo arrastado.

Nesta figura verificamos que o aumento no percentual de água adicionada para hidratação não proporciona melhoria no percentual de óleo arrastado.

\subsection{Avaliação do comportamento da pressão no arreste do óleo}

Nesta análise foram mantidas constantes a vazão de alimentação de óleo bruto, a composição do mesmo e a dosagem a $4 \%$ de água, variando apenas a pressão contra corrente de saída do óleo. Os resultados do arraste de óleo em relação a variação de pressão estão expostos na Figura 7.

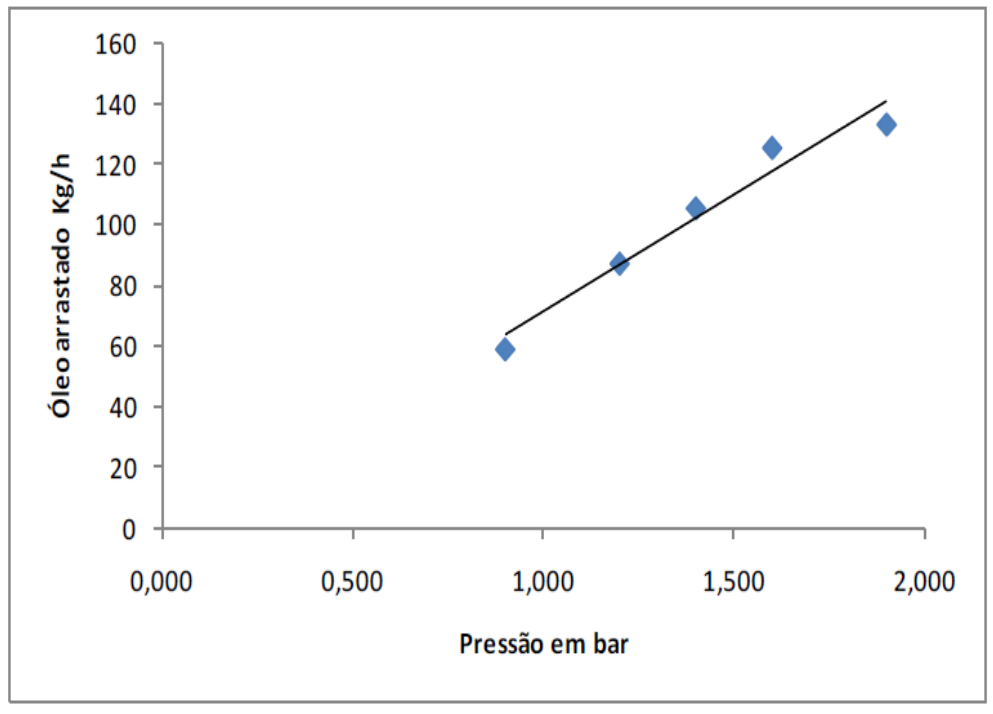

Figura 7. Variação da pressão em relação ao óleo arrastado 
Nesta figura foi verificada uma influência significativa entre aumento da pressão e o arraste do óleo. De acordo com Erickson (1987) a eficiência de separação pode ser alcançada durante a operação por meio de ajuste da pressão de contra corrente de descarga do óleo. Desta forma foi evidenciado, que a pressão é um parâmetro do processo de centrifugação que contribui diretamente no rendimento de perdas por arraste de óleo na corrente de gomas.

\section{Conclusões}

As análises realizadas nas amostras coletadas apresentaram resultados compatíveis nos descritos na literatura para as correntes de entrada de saída. O processo de degomagem foi representado satisfatoriamente pelo modelo matemático desenvolvido. Apresentando resultados experimentais e calculada com desvios inferiores a $5 \%$.

O parâmetro operacional de dosagem de água não exerceu influência sobre o arraste de óleo na corrente de gomas e na purificação do óleo degomado. Logo é possível trabalhar na redução do teor de água adicionada no processo industrial em análise, pois este processo opera com dosagens superiores a $4 \%$.

O parâmetro operacional de ajuste de pressão influencia diretamente na perda de óleo arrastado na corrente de gomas. 


\section{Bibliografia}

AOCS.1998. Official Methods and Recommended Practices of the American Oil Chemists Society. 5th edn., Firestone D (Ed.),AOCS Press, Champaign.

BIRD, R. B.,Stewart E.W.,Lightfoot N.E. (2005). Macroscopic Balances for Multicomponent Systems.In:Transport Phenomena. Second Edition

DIKSTRA, J. A.(2000). Desgomado, refinación, lavado y secado de aceites y grasas. Libro de Oro de A\&G - $10^{\circ}$ Aniversario - Tomo II: Recopilación de Artículos Técnicos, Asociación Argentina de Grasas y Aceites, n. 10, p.13-29.

DORSA, R.(2004). Tecnologia de Óleos Vegetais. Westfalia Separator do Brasil, Campinas:Ideal.

ERICKSON, D.R.(2000). Aspectos críticos en la refinación del aceite de soja. Libro de Oro de A\&G - $10^{\circ}$ Aniversario - Tomo II: Recopilación de Artículos Técnicos, Asociación Argentina de Grasas y Aceites, n. 10, p.30-38.

FOUST,A.WENZLE,L.A.,CLUMP,C.W.,MAUS,L.,BRYCE,A.L.(2000).Princípios das Operações Unitárias. Rio de Janeiro: Guanabara Dois S.A. , p. 539-554

HARTEN, B.; EICKHOFF, K. P.(2000). El uso de Decantadoras y Separadoras Centrífugas en la Industria Oleoquímica. Libro de Oro de A\&G - $10^{\circ}$ Aniversario - Tomo III: Recopilación de Artículos Técnicos, Asociación Argentina de Grasas y Aceites, n. 10, p.35-48.

PARAÍSO, P. R. ; CAUNETO, H. ; ANDRADE, C. M. G. ; ZEMP, R. J.(2008) . Modeling and simulation of the soybean oil meal desolventizing-toasting process. Journal of Food Engineering, v. 86, p. 334-341.

PARAÍSO, P. R. ; ANDRADE, C. M. G. ; ZEMP, R. J. (2005) Destilação da Miscela II:

Modelagem e Simulação do Stripping do Hexano. Boletim da Sociedade Brasileira de Ciência e Tecnologia de Alimentos, Campinas, v. 25, n.1, p. 37-44.

PARAÍSO, P. R. ; ANDRADE, C. M. G. ; ZEMP, R. J.(2003) .Destilação da Miscela I:

Modelagem e Simulação da Evaporação do Hexano. Boletim da Sociedade Brasileira de Ciência e Tecnologia de Alimentos, v. 3, n.23, p. 459-467.

PARAÍSO, P. R. ; ANDRADE, C. M. G. ; ZEMP, R. J.(2002) . Análise Energética do Processo de Obtenção do óleo de Soja. Revista Tecnológica (UEM), Universidade Est. de Maringá, v. 11, p. 25-36.

PERRY, R. H.,CHILTON, C.H. (1984) Chemical Engineers' Handbook, 5 ed., McGraw-Hill

Kogakusha Ltd, Tokyo.

KEMPER, G. T.(1998). Minimização da perda de solvente. Grãos \& Óleos, p. 22,

Setembro/Outubro.

KEMPER, G.T.(2000) Innovations in Meal Desolventizing, In: American Oils Chemists

Society, 91,San Diego,. Proceedings. AOCS. 